\title{
Optimal Dosage of Naoh Regarding the Solution Temperature during Corn Starch Gelatinization
}

\author{
André Carlos Silva ${ }^{1}$, Débora Nascimento Sousa ${ }^{2}$, Elenice Maria Schons Silva ${ }^{3}$, Thales Prado Fontes ${ }^{4}$, \\ Raphael Silva Tomaz ${ }^{5}$, Mariana Resende Barros ${ }^{6}$ \\ ${ }^{1,3,6}$ Federal University of Goiás, Department of Mine Engineering \\ Av. Dr. Lamartine Pinto de Avelar, 1120, Catalão, Brazil \\ ancarsil@ufg.br; eschons@ufg.br; mrezendeb@outlook.com \\ $2,4,6$ Goiano Federal Institute, Department of Mining \\ Av. Vinte de Agosto, 410, Catalão, Brazil \\ debora.nascimento@ifgoiano.edu.br; thales.prado@ifgoiano.edu.br; raphael.tomaz@ifgoiano.edu.br
}

\begin{abstract}
Starches are widely used as depressant in froth flotation operations in Brazil due to their efficiency, increasing the selectivity in the inverse flotation of quartz depressing iron ore. Starches market have been growing and improving in recent years, leading to better products attending the requirements of mineral industry. The major source of starch used for iron ore is the corn starch, which need to be gelatinized, by heat or sodium hydroxide $(\mathrm{NaOH})$ addition, prior its use. This stage has a direct impact on industrials costs, once the lowest consumption of $\mathrm{NaOH}$ in gelatinization provides better control of the $\mathrm{pH}$ in the froth flotation and reduce the amount of electrolytes present in the pulp. In order to evaluate the influence if the temperature in the $\mathrm{NaOH}$ consumption gelatinization tests were carried out with temperatures ranging from 25 to $65^{\circ} \mathrm{C}$, measuring the volume of $\mathrm{NaOH}$. All tests were performed in triplicate. A linear model correlating the temperature and the $\mathrm{NaOH}$ need for the corn starch gelatinization had been stablished. This model can allow mineral industries to optimize the $\mathrm{NaOH}$ amount used to prepare the depressant to be used in froth flotation. For example, the reduction in $\mathrm{NaOH}$ could easily reaches $480 \mathrm{~L}$ per ton of corn starch when performing gelatinization with corn starch solution at $35^{\circ} \mathrm{C}$ when compared to $25^{\circ}$ C.
\end{abstract}

Keywords: froth flotation, gelatinization, corn starch, sodium hydroxide, temperature

\section{Introduction}

Corn starch is the default depressant for iron ore since 1978. Modified cornstarches are composed by amylopectin (70$80 \%$ ) and amylose (20-30\%) without impurities such as fibres, mineral matter, oils and proteins normally present in conventional starches [1]. The authors point out that oil (triglycerides) present in conventional starch act as an antifoam agent spoiling the flotation process if its content exceeds $1.8 \%$. The starch's depressant action is due to the coating of a natural low energy hydrophobic mineral surface with a hydrophilic film to prevent the attachment of air bubbles [2].

Studies showing the importance of the amylose/amylopectin ratio in starch during hematite depression point out that amylopectin reduces the hematite froth flotation more profoundly than amylose when a primary ether amine is used as a collector [3]. The effectiveness of the alkali gelatinization is strongly affected by the starch/ $\mathrm{NaOH}$ ratio used in the gelatinization [4] and the dissolution technique [5], being the typical ratio 5:1 [4], [6]. Some studies suggest that the starch solution was designed to yield a maximum concentration of $0.1 \% \mathrm{w} / \mathrm{w}$ and must be prepared daily to avoid the retrogradation [7], [8]. However, this is not well stablished and other studies disagree using concentrations up to $3 \%$ [9].

The temperature needed for gelatinization decreases with increasing of the amylopectin content. Retrogradation occurs spontaneously when starch solutions are stored at low temperatures at neutral $\mathrm{pH}$. Amylose's retrogradation may occur within a period of four to five hours after the gelatinization, while the amylopectin retrogrades only 10\% within 100 days [10].

The primary adsorption mechanisms of starch on hematite were proposed as non-selective hydrogen bonding and electrostatic forces, mainly because of the presence of a large number of hydroxyl groups in starch molecules and on hematite surface. As confirmed by several studies, starch adsorbs more on hematite surface than on quartz [11]. The adsorption density of starch on quartz surface is approximately 10 times less than that on hematite [12]. For pH's higher than eight, the starch adsorption is almost non-existent on non-activated quartz surface, while it is noticeable on hematite surface. The reasons for 
this selectivity are a better ability of hematite surface to form hydrogen bonds with the depressant and the fact that quartz surface is more negative than hematite, being the macromolecules slightly negative because of OH- adsorption [3]. In the other hand, the starch adsorption on hematite increases as the $\mathrm{pH}$ value decrease [7].

Other vegetable species, such as cassava, potato, wheat, rice, arrowroot, can produce starch with potential to be used in flotation. The most attractive among them, considering the cost of production, is cassava, which grows widely in warm weather countries, with no need of fertilizers or soil correction. The major obstacle to its use is the absence of major suppliers. The starch fraction content (amylopectin + amylose) extracted from cassava is higher than in corn because proteins and oil contents are lower in cassava, which prevents the risk of froth suppression. Cassava starch shows higher viscosities than corn starch, an indication of higher molecular weight, which can lead to more effective depressant action [6]. Potato flour has been used industrially in Europe, but there are no records of its use in the mining industry so far, mainly due the fact that potato degrades much faster than corn and have a high price [13].

\section{Methodology}

The first stage aimed to characterize the corn starch sample (donate by Cargill) in order to better understand its gelatinization. To determine the amylose content a method proposed by the American Association of Cereal Chemists (AACC) number 1995 was used, which is a simple colorimetric procedure. Samples of corn starch were added to a solution of $1 \mathrm{~mL}$ of acetic acid at 1 mol. $\mathrm{L}^{-1}$ and $2 \mathrm{~mL}$ of solution of iodine-potassium iodide, which reacts with starch to form a blue coloured complex. This complex is developed due to the imprisonment of iodine inside the chain of amylose. The solution was then stored for 30 minutes in a dark room and then using a spectrophotometer Biospectro, model SP220 read the absorbance at $620 \mathrm{~nm}$. The content of amylose was calculated using the absorbance values read and a calibration curve made with pure amylose (supplied by Sigma-Aldrich) in the range of $0.004-0.024 \mathrm{mg} \cdot \mathrm{mL}^{-1}$ (for this curve the obtained fit was $\mathrm{r}^{2}$ $=0.998$ ). The results were expressed in $\mathrm{mg} \cdot \mathrm{mL}^{-1}$ and performed in triplicate.

Corn starch swelling power and solubility were also measured to calculate the amylose content in it. When starch molecules are heated in water, the crystalline structure is broken and the water molecules form hydrogen bonds between amylose and amylopectin, exposing its hydroxyl groups. This causes an increase in the granule size (a swelling) and in its solubility [14]. This swelling power and solubility varies according to the starch source, providing evidence of the interaction between the starch chains within the amorphous and crystalline domains. The extension of these interactions is influenced by the ratio amylose/amylopectin due to molecular features distributed, molecular weight, degree, length of branches [15].

The swelling power was obtained by the relation between the final mass swelled and the starch initial mass. The starch solubility was calculated by the relation between the soluble mass and initial amount of starch (expressed in percentage). Finally, the temperature influence in the $\mathrm{NaOH}$ consumption was stablished through experiments using both solution temperature control and $\mathrm{NaOH}$ addition to it, avoiding the excessive use of $\mathrm{NaOH}$. Corn starch samples of $20 \mathrm{~g}$ were placed in a $600 \mathrm{~mL}$ beaker on top of a heating plate Ika C MAG HS 4. Then $200 \mathrm{~mL}$ of distilled water at pH 7 and different temperatures (ranging from 25 to $65^{\circ} \mathrm{C}$ ) were added to the sample and the solution was kept under agitation at 1,200 RPM using a mechanical stirrer Fisatom 712 to promote a complete dilution of the starch sample. A pH meter Hanna Instruments HI2221 was installed in order to read the solution $\mathrm{pH}$ and to provide temperature control. After the complete dilution of the corn starch sample, the initial $\mathrm{pH}$ value was noted and the titration started. An aliquot of $1 \mathrm{~mL}$ of $10 \% \mathrm{NaOH}$ solution was added every 2 minutes to the corn starch solution. Before a new addition of the $\mathrm{NaOH}$ solution, the $\mathrm{pH}$ was noted. The process was repeated until the point that the starch solution presented itself viscous and more transparent (also known as the turning point of the gelatinization). Four steps of the gelatinization process can be seen in figure 1 . All titration process was performed in triplicate.

\section{Results and Discussion}

As expected, the corn starch samples showed $71.62 \%$ of amylose and amylopectin $28.38 \%$. The amylose/amylopectin ratio determines many properties of starches, such as clarity, viscosity, texture, tendency to retrogradation, ability to resist to acids, stirring and temperature extremes. Amylose is an essentially linear molecule consisting of D-glucose units linked with a small amount of branching. In contrast, amylopectin is a highly branched molecule composed by chains with many lengths of D-glucose units linked. corn starch samples showed solubility equal to $12.57 \%$ and swelling power of $22.85 \%$. These values are significantly low compared to other starches. It has been proven in the literature that high amylose starches show limited solubility and swelling power, even after a prolonged heating time [16]. 


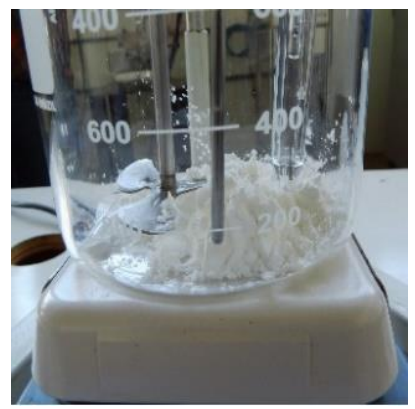

(a)

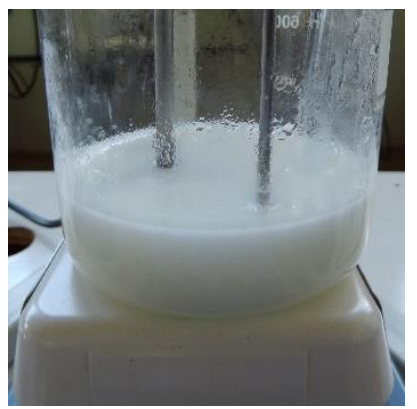

(b)

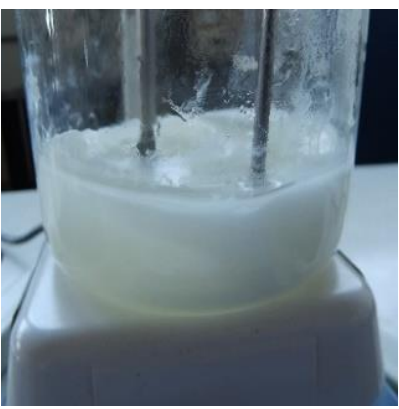

(c)

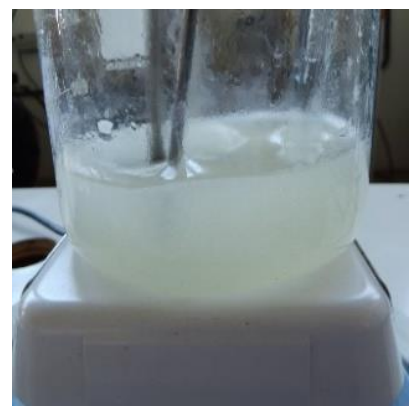

(d)

Fig. 1: Four steps in the starches and flours alkaline gelatinization process. (a) corn starch sample, (b) corn starch solution after complete solubilization, (c), step in the titration process and (d) complete gelatinization of the corn starch sample.

Figure 2 shows the $\mathrm{NaOH}$ volume consumed in the corn starch gelatinization at different solution temperatures. As expected, the $\mathrm{NaOH}$ volume needed for the corn starch gelatinization decreases with the increase of the temperature. An experiment at $65^{\circ} \mathrm{C}$ was performed in absence of $\mathrm{NaOH}$, being this the minimum temperature required for corn starch gelatinization in absence of $\mathrm{NaOH}$. Temperatures lower than $25^{\circ} \mathrm{C}$ were not considered. It is well known in the literature that the greater the proportion of amylopectin the lower the temperature required for the starch gelatinization [10]. A linear model was obtained with fit $\left(\mathrm{r}^{2}\right)$ around $98 \%$, which can be considered adequate. It is also possible to notice that the experimental errors (represented by the standard deviation) in the $\mathrm{NaOH}$ consumed where lower than $0.65 \mathrm{~mL}$.

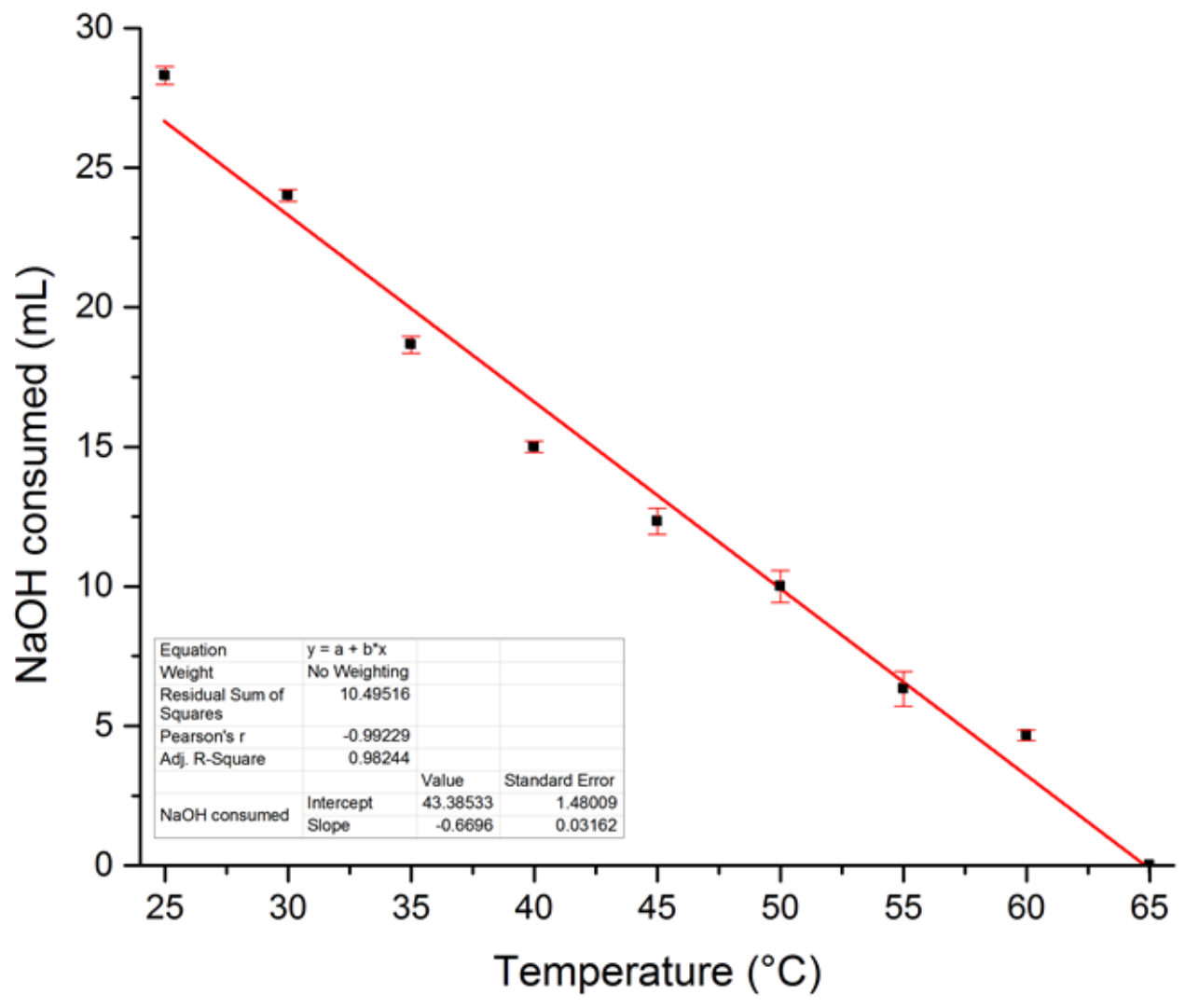

Fig. 2: Influence of the temperature in the $\mathrm{NaOH}$ consumption for corn starch gelatinization.

Table 1 shows the average initial and final $\mathrm{pH}$ for the gelatinization tests and the average $\mathrm{NaOH}$ consumed at the turning point. It is possible to notice that corn starch acidify the solution the solution after its dilution in the begging of the process. At the turning point, the average $\mathrm{pH}$ of the solution was above 12 for all tested temperatures, except for $65^{\circ} \mathrm{C}$. This happened because no $\mathrm{NaOH}$ was added to the solution and therefore the $\mathrm{pH}$ remained the same. 
Table 1: Average initial and final $\mathrm{pH}$ for the gelatinization tests and average $\mathrm{NaOH}$ consumed at turning point.

\begin{tabular}{|c|c|c|c|c|}
\hline $\begin{array}{c}\text { Temperature } \\
\left({ }^{\circ} \mathrm{C}\right)\end{array}$ & $\begin{array}{c}\text { Average initial } \\
\mathrm{pH}\end{array}$ & $\begin{array}{c}\text { Average } \mathrm{pH} \text { at } \\
\text { turning point }\end{array}$ & $\begin{array}{c}\text { Average } \mathrm{NaOH} \text { consumed at } \\
\text { the turning point }(\mathrm{mL})\end{array}$ & $\begin{array}{c}\text { Standard deviation of } \mathrm{NaOH} \\
\text { consumption }\end{array}$ \\
\hline 25 & 5.53 & 12.87 & 28.3 & 0.32 \\
\hline 30 & 5.36 & 12.73 & 24.0 & 0.21 \\
\hline 35 & 5.19 & 12.91 & 18.7 & 0.30 \\
\hline 40 & 5.17 & 12.83 & 15.0 & 0.20 \\
\hline 45 & 5.29 & 12.77 & 12.3 & 0.47 \\
\hline 50 & 5.32 & 12.46 & 10.0 & 0.58 \\
\hline 55 & 5.52 & 12.09 & 6.3 & 0.62 \\
\hline 60 & 5.31 & 12.01 & 4.7 & 0.19 \\
\hline 65 & 5.21 & 5.21 & 0.0 & 0.00 \\
\hline
\end{tabular}

\section{Conclusion}

The use of $\mathrm{NaOH}$ titration presented itself as an easy, but powerful, tool for study the $\mathrm{NaOH}$ consumption needed in the gelatinization of the corn starch showing a linear relation between temperature and $\mathrm{NaOH}$ consumption. Understanding this relation is critical for mineral processing, specifically to froth flotation, since it may be possible to achieve a complete gelatinization of corn starch with lower amounts of $\mathrm{NaOH}$ by changing the temperature. A difference in $5^{\circ} \mathrm{C}$ (from 25 to $30^{\circ} \mathrm{C}$, acceptable for Brazilian weather) means that is possible to reduce $215 \mathrm{~L}$ of NaOH (solution $10 \%$ ) per ton of corn starch in its gelatinization. If the temperature different was even higher, for example a temperature possible to be reached in Brazil's summer such as $35^{\circ} \mathrm{C}$, the reduction in $\mathrm{NaOH}$ could easily reaches $480 \mathrm{~L}$ per ton of corn starch.

\section{Acknowledgements}

The authors thank financial support from the Brazilian agencies CNPq, CAPES, FAPEG and FUNAPE. In addition, we like to thank Cargilll for the samples donation, Federal University of Goiás and Goiano Federal Institute.

\section{References}

[1] A. E. C. Peres and M. I. Corrêa, "Depression of iron oxides with corn starches," Minerals Engineering, vol. 9, no. 12, pp. 1227-123, 1996.

[2] C. L. L. Pinto, A. C. Araújo, and A. E. C. Peres, "The effect of starch, amylose and amylopectin on the depression of oxi-minerals," Minerals Engineering, vol. 5, no. 3-5, pp. 469-478, 1992.

[3] H. D. G. Turrer and A. E. C. Peres, "Investigation on alternative depressants for iron ore flotation," Minerals Engineering, vol. 23, no. 11-13, pp. 1066-1069, 2010.

[4] I. Iwasaki and R. W. Lai, "Starches and starch products as depressants in soap flotation of activated silica from iron ores," Trans. Am. Inst. Min. Metall. Pet. Eng., vol. 232, no. 364, pp. 364-371, 1965.

[5] L. S. Leal Filho, S. M. Assis, A. C. Araújo, and A. P. Chaves, "Process mineralogy studies for optimizing the flotation performance of two refractory phosphate ores," Minerals Engineering, vol. 6, no. 8-10, pp. 907-917, 1993.

[6] L. O. Fillipov, V. V. Severov, and I. V. Fillippova, "Mechanism of starch adsorption on Fe-Mg-Al-bearing amphiboles," International Journal of Mineral Processing, vol. 123, pp. 120-128, 2013.

[7] I. Iwasaki, W. J. Carlson, and S. M. Parmeter, "The use of starches and starch derivatives as depressants and flocculants in iron ore beneficiation," Trans. ASME-AIME, vol. 224, pp. 88-98, 1969.

[8] R. C. Guimarães, A. C. Araújo, and A. E. C. Peres, "Reagents in igneous phosphate ores flotation," Minerals Engineering, vol. 18, no. 2, pp. 199-204, 2005.

[9] S. R. B. Cooke, N. F. Schultz, and E. W. Lindroos, "The effect of certain starches on quartz and hematite suspensions," Trans. AIME., vol. 193, pp. 697-698, 1952.

[10] Q. Liu, Y. Zhang, and J. S. Laskowski, "The adsorption of polysaccharides onto mineral surfaces: an acid/base interaction," International Journal of Mineral Processing, vol. 60, no. 3-4, pp. 229-245, 2000.

[11] N. S. Mikhailova, "Research of interaction of starch with oxides and silicates," Obogashenie rud., vol. 6, pp. 20-23, 1972. 
[12] P. R. G. Brandão, L. G. Caires, and D. S. B. Queiroz, "Vegetable lipid oil based collectors in the flotation of apatite ores," Minerals Engineering, vol. 7, no. 7, pp. 917-925, 1994.

[13] S. S. Ibrahim and N. A. Abdel-Khalek, "The action of different types of corn starch on the flocculation of phosphate slimes," Minerals Engineering, vol. 5, no. 8, pp. 907-916, 1992.

[14] C. C. Denardin and L. P. Silva, "Estrutura dos grânulos de amido e sua relação com propriedades físico-químicas," Revista Ciência Rural, vol. 39, no. 3, pp. 945-954, 2009.

[15] H. W. Leach, L. D. McCowen, and T. J. Schoch, "Structure of starch granule - I. Swelling and solubility patterns of various starches," Cereal Chemistry, vol. 36, no. 6, pp. 534-544, 1959.

[16] P. K. Weissenborn, "Behaviour of amylopectin and amylose components of starch in the selective flocculation of ultrafine iron ore," International Journal of Mineral Processing, vol. 47, no. 3-4, pp. 197-211, 1996.

[17] L. O. Fillipov, V. V. Severov, and I. V. Fillippova, "An overview of the beneficiation of iron ores via inverse cationic flotation,” International Journal of Mineral Processing, vol. 127, pp. 62-69, 2014.

[18] N. Singh, J. Singh, L. Kaur, N. S. Sodhi, and B. S. Gill, "Morphological, thermal and rheological properties of starches from different botanical sources," Food Chemistry, vol. 81, no. 2, pp. 219-231, 2003.

[19] M. Tang and Q. Liu, "The acidity of caustic digested starch and its role in starch adsorption on mineral surfaces," International Journal of Mineral Processing, vol. 112-113, pp. 94-100, 2012.

[20] B. Kar, H. Sahoo, S. S. Rath, and B. Das, "Investigations on different starches as depressants for iron ore flotation," Minerals Engineering, vol. 49, pp. 1-6, 2013.

[21] J. B. Clemmer, "Flotation of Iron Ore," in 8th Annual Mining Symposium, Duluth, Minnesota: USA. 1947.

[22] M. Wootton and P. Ho, "Alkali gelatinisation of wheat starch," Starch, vol. 41, no. 7, pp. 261-265, 1989.

[23] F. K. Broome, C. W. Hoerr, and H. J. Harwood, "The binary systems of water with dodecylammonium chloride and its N-methylderivated," J. Am. Chem. Soc., vol. 73, pp. 3350-3352, 1951. 